\title{
Silymarin mitigates diclofenac-induced liver toxicity through inhibition of inflammation and oxidative stress in male rats
}

\author{
Pantea Ramezannezhad $^{1}{ }^{\mathbb{D}}$, Ali Nouri $^{* *}{ }^{\mathbb{D}}$, Esfandiar Heidarian $^{2}$ \\ ${ }^{1}$ Medical Plants Research Center, Basic Health Sciences Institute, Shahrekord University of Medical Sciences, Shahrekord, Iran \\ ${ }^{2}$ Clinical Biochemistry Research Center, Basic Health Sciences Institute, Shahrekord University of Medical Sciences, Shahrekord, Iran
}

\section{A R T I C L E I N F 0}

Article Type:

Original Article

\section{Article History:}

Received: 4 March 2019

Accepted: 7 April 2019

\section{Keywords:}

Diclofenac

Liver toxicity

Silymarin

Oxidative stress

TNF- $a$

\begin{abstract}
A B S T RAC T
Introduction: Diclofenac (DIC) is one of the compounds derived from acetic acid which is known for its anti-inflammatory and analgesic attributes. Silymarin is a flavonoid compound which is derivate from Silybum marianum seeds. This research was done to assess the protective role of silymarin against liver toxicity induced by DIC in male rats.

Methods: Randomly, 40 male Wistar rats were assigned into five groups as follows: Group 1: control group, Group 2: DIC-only treated (50 mg/kg, i.p), Group 3: silymarin-only treated (200 $\mathrm{mg} / \mathrm{kg}$, p.o); Groups 4 and 5: DIC (50 mg/kg, i.p) plus silymarin (100 mg/kg and $200 \mathrm{mg} / \mathrm{kg}$, p.o, respectively) treated. Various biochemical, molecular, and histological parameters were evaluated in serum and tissue.

Results: In the DIC-only treated group, the levels of liver glutathione peroxidase (GPx), superoxide dismutase (SOD), intracellular glutathione (GSH) and catalase (CAT) significantly diminished and the levels of total bilirubin, alkaline phosphatase (ALP), nitrite, alanine aminotransferase (ALT), malondialdehyde (MDA), serum tumor necrosis factor- $\alpha$ (TNF- $\alpha$ ), aspartate aminotransferase (AST), and TNF- $\alpha$ gene expression were remarkably elevated relative to control animals. In other hands, treatment with silymarin caused a noticeable elevation in GPx, SOD, GSH, CAT and a remarkable reduction in levels of total bilirubin, ALP, nitrite content, ALT, MDA, serum TNF- $\alpha$, AST and TNF- $\alpha$ gene expression relative to DIC-only treated group. Histopathological injuries were also improved by silymarin administration.

Conclusion: The results confirm that silymarin has an ameliorative effect on liver toxicity induced by DIC and oxidative stress in male rats.
\end{abstract}

Implication for health policy/practice/research/medical education:

The present study showed that silymarin mitigates DIC-induced liver toxicity through inhibition of inflammation and oxidative stress in male rats. After clinical trials, silymarin may be used with DIC as a complementary drug for decreasing the toxicity of DIC.

Please cite this paper as: Ramezannezhad P, Nouri A, Heidarian E. Silymarin mitigates diclofenac-induced liver toxicity through inhibition of inflammation and oxidative stress in male rats. J Herbmed Pharmacol. 2019;8(3):231-237. doi: 10.15171/jhp.2019.34.

\section{Introduction}

Drug induced liver toxicity is one of the main worries for pharmaceutical industry and physicians (1). Non-steroidal anti-inflammatory drugs have anti-inflammatory and analgesic properties that are widely prescribed and some of them cause liver toxicity (2,3). Diclofenac (DIC) belongs to Non-steroidal anti-inflammatory drug family and it is one of the compounds derived from phenyl acetic acid but liver toxicity is one of the main concerns for this drug (4). The mechanism of liver toxicity induced by DIC has been partly associated to mitochondrial damage $(5,6)$, disruption of antioxidant defense system
(7), change in the integrity of covalent protein by reactive metabolites (8), and the mechanisms mediated by the immune system (9). DIC is listed under FDA black box warning for cardiovascular toxicity and liver toxicity with mitochondrial liabilities (10). Therefore, any therapeutic agent which can suppress any of the pathological pathways activated by DIC might be used to prevent or inverse its toxic action.

Silymarin is a flavonoid compound which is derivate from Silybum marianum seeds. It is a combination of silydianine, silychristine, silibinin and isosilybinin (11). Previous studies have shown that silymarin has 
antioxidant and anti-inflammatory properties $(12,13)$. This research was aimed to assess the noxious effect of DIC intoxication on the liver through serum biochemical markers, oxidative stress, gene expression of tumor necrosis factor- $\alpha$ (TNF- $\alpha$ ), histological alterations and protective role of silymarin on DIC intoxication in rats.

\section{Materials and Methods}

\section{Chemicals}

2-thiobarbituric acid, sodium acetate, and $\mathrm{H}_{2} \mathrm{O}_{2}$ were prepared from Merck company (Darmstadt, Germany). Silymarin, 5,5-dithiobis-2-nitrobenzoic acid, griess reagent, GSH, nitro blue tetrazolium and TPTZ (2,4,6-tripyridyl-s-triazine) were purchased from Sigma (St. Louis, MO). SYBR Green Real Time-PCR Master Mix was provided from Qiagen Co. (Dusseldorf, Germany). Total bilirubin, alkaline phosphatase (ALP), aspartate aminotransferase (AST) and alanine aminotransferase (ALT) were evaluated using kits of Pars Azmun co (Tehran, Iran). All other chemicals which employed in this study were of analytical grade.

\section{Animals}

Forty male Wistar rats weighting around $220 \mathrm{~g}$ (6-8 week old) were applied for this research. The experimental rats were obtained from Jondishapour University (Ahwaz, Iran). The rats were kept under $25^{\circ} \mathrm{C}$ ambient temperature, $50 \%$ relative humidity and a dark- light cycle (12 hours) and were allowed free access to water and standard diet. All methods were confirmed by the Ethics Committee of Shahrekord University of Medical Sciences Ethics Committee, Shahrekord, Iran (Ethic number IR.SKUMS. REC.94.146).

\section{Experimental design}

Randomly, 40 male Wistar rats were assigned into five groups each comprising of eight animals and treated for 5 days. Group 1 (control group) was treated with normal saline ( $1 \mathrm{~mL} / \mathrm{kg}$, i.p.). Group 2 received DIC only $(50 \mathrm{mg} /$ $\mathrm{kg}$ bw, i.p.) (14). Group 3 received silymarin only (200 $\mathrm{mg} / \mathrm{kg}$ ). Group 4, 5 received DIC (50 mg/kg bw, i.p.) plus silymarin $(100,200 \mathrm{mg} / \mathrm{kg}$ bw, p.o, respectively) (15-17). At the end of our study, fasted rats were killed under mild chloroform anesthesia. Whole blood specimens were gathered by cardiac puncture procedure to obtain serum and plasma. Also, liver tissue was removed for determining liver catalase (CAT), superoxide dismutase (SOD), and glutathione peroxidase (GPx) activities, nitrite content, lipid peroxidation, gene expression of TNF- $\alpha$, and histological studies.

Biochemical analysis

Serum biochemical markers such as total bilirubin, ALP, AST and ALT contents were measured by an enzymatic method (Pars Azmun kit, Pars Azmun Co., Tehran, Iran) using autoanalyzer (BT 3000, Biotecnica, Cergy Pontoise Cedex, France).

Determination of ferric reducing/antioxidant power (FRAP)

Ferric reducing/antioxidant power was determined by Heidarian and Soofiniya procedure (18). Brifly, plasma was mixed with FRAP reagent (composed of: $25 \mathrm{ml}$ acetate buffer, $2.5 \mathrm{ml} \mathrm{TPTZ}$ solution and $2.5 \mathrm{ml} \mathrm{FeCl} 3$ ) then 10 minutes incubated at 37 centigrade degree and optical density of blue color was measured at $593 \mathrm{~nm}$. FeSO4 was used as a standard of FRAP assay at a concentration range between 100 and $1000 \mu \mathrm{M}$. The results are reported as $\mu \mathrm{mol} / \mathrm{L}$.

Determination of nitrite content

Content of nitrite was evaluated using a griess reagent (19). Briefly, liver supernatant was blended with griess reagent (composed of: $0.1 \% \mathrm{~N}$-(1-naphthyl) ethylene diamine, $1.0 \%$ sulfanilamide and $2.5 \%$ orthophosphoric acid) then, 30 minutes incubated at 37 centigrade degree and light absorbance was measured at $548 \mathrm{~nm}$. Content of nitrite was assessed using standard curve of sodium nitrite and was reported as $\mu \mathrm{M} / \mathrm{mg}$ tissue.

\section{Determination of lipid peroxidation}

MDA contents in rat liver and serum were determined by the TBA reactive substance test as described previously (18). Briefly, plasma or supernatant was mixed with sodium dodecyl sulfate $(8.1 \%)$ and TBA/buffer (composed of: of $0.53 \%$ thiobarbituric acid in $20 \%$ acetic acid as adjusted to $\mathrm{pH} 3.5$ with $\mathrm{NaOH}$ ) then, 60 minutes incubated at 95 centigrade degree. The reaction was stopped by placing tubes on ice followed by centrifugation at $4000 \mathrm{rpm}$ for 10 minutes. The optical density of pink color was measured at $532 \mathrm{~nm}$. 1, 1, 3, 3-tetraethoxypropane was used as a standard of MDA assay. The measurements were done in duplicates and the results were expressed in $\mu \mathrm{mol} / \mathrm{L}$.

Determination of intracellular GSH levels Intracellular GSH contents were determined using of Ellman method (20). In this procedure 5,5-dithiobis-2nitrobenzoic acid reacts with GSH and the optical density has a peak value at $410 \mathrm{~nm}$. Data were reported as $\mu \mathrm{mol} / \mathrm{g}$ tissue.

\section{Tissue GPx activity}

The activity of GPx was assayed by determining the reduction of GSH level after adding the sample in the presence of $\mathrm{H}_{2} \mathrm{O}_{2}$ and $\mathrm{NaN} 3$ (21).

Determination of tissue CAT and SOD activities The liver CAT activity of experimental groups was measured as described previously by Heidarian et al (22). Briefly, $\mathrm{H}_{2} \mathrm{O}_{2}$ solution (composed of: $10 \mathrm{mmol} \mathrm{H}_{2} \mathrm{O}_{2}$ 
in $50 \mathrm{mM}$ phosphate buffer, $\mathrm{pH}$ 7.4), and homogenate was pipetted into a cuvette. The reduction of $\mathrm{H} 2 \mathrm{O} 2$ was followed at a wave length of $240 \mathrm{~nm}$ for 2 minutes. The activity of liver SOD was evaluated using the inhibition of the NBT photo chemical reaction at $560 \mathrm{~nm} \mathrm{(23).} \mathrm{All}$ total protein samples were assessed using the method of Bradford (24).

\section{Determination of serum TNF- $\alpha$}

Serum TNF- $\alpha$ was assessed using the ELISA assay kit (BTLaboratory, China) according to the procedure provided by the manufacturer.

\section{Determination of TNF- $\alpha$ gene expression}

The mRNA was extracted using the BIOZOL kit reagent (Bioer, China) according to the instructions. Quality and quantity of total RNA were measured by absorbance of 260/280 $\mathrm{nm}$ using a spectrophotometer by the Nanodrop2000 (Thermo USA). cDNA measurement was done by the PrimeScript ${ }^{\mathrm{TM}}$ reagent kit (Takara Bio Inc. Japan) and in accordance with the instructions. Then, cDNA amplified according to RT-qPCR and using SYBR $^{\circledR}$ Green PCR Master Mix in the presence of specific primers for TNF-a (forward: 5'-CTGGCGTGTTCATCCGTTC-3', reverse: 5'-GGCTCTGAGGAGTAGACGATAA-3') and $\beta$-actin (forward: 5'-CTTCTACAATGAGCTGCGTGTGGCC-3', reverse: 5'-GGAGCAATGATCTTGATCTTCATGG-3'). Primers after design with Oligo 7.0 software was approved using Blast-Nucleotide (NCBI). PCR carried out in primary denaturation at $95^{\circ} \mathrm{C}$ for 10 minutes. RT-q PCR was performed in 40 cycles (including secondary denaturation at 15 seconds at $95^{\circ} \mathrm{C}, 20$ seconds at $60^{\circ} \mathrm{C}$ for annealing, 25 seconds for $72^{\circ} \mathrm{C}$ for extension). $\beta$-actin gene was used as an internal control gene to control the expression of mRNA. Also, $\Delta \Delta \mathrm{CT}$ method was used for the analysis of gene expression.

Histopathological study

A segment of each liver was fixed in 10\% formalin solution. All samples were embedded in paraffin and $5 \mu \mathrm{m}$ thickness sections were prepared. Then, the slices stained with hematoxylin-eosin ( $\mathrm{H} \& \mathrm{E}$ ) for histopathological observation $(25,26)$.

\section{Statistical analysis}

One-way analysis of variance (ANOVA) was used for data analysis using SPSS software (Statistical Package for the Social Sciences, version 20.0, SPSS Inc, Chicago, IL). All data were expressed as mean $\pm \mathrm{SD}$. Also, $\Delta \Delta \mathrm{CT}$ method was used for the analysis of TNF- $\alpha$ gene expression. Mean values of the groups were compared using the Tukey post hoc test. $P<0.05$ was statistically considered significant.

\section{Results}

Effects of silymarin on serum ALT, AST, ALP and total bilirubin

Table 1 shows the effects of DIC and silymarin on total bilirubin, ALP, AST and ALT in serum. Injection of DIC in DIC-only treated group led to a noticeable elevation $(P<0.05)$ in serum ALT, AST, ALP and total bilirubin relative to control animals (Table 1). However, administration of silymarin led to noticeable decline $(P<0.05)$ in ALT, AST, ALP and total bilirubin in animals exposed to DIC.

Effects of silymarin on plasma FRAP, Nitrite content and MDA levels

The effects of silymarin on MDA levels, Nitrite content and plasma FRAP are shown in Table 2. In the DIC-only treated group, injection of DIC resulted in a remarkable decrease $(P<0.05)$ in plasma FRAP and a noticeable increase in nitrite content, liver MDA and serum MDA contents relative to control animals. Treatment with silymarin caused a noticeable elevation $(P<0.05)$ in plasma antioxidant capacity (FRAP) and a noticeable decrease $(P<0.05)$ in nitrite content, liver MDA and serum MDA contents in animals exposed to DIC.

Effects of silymarin on CAT activity, SOD activity, GPx activity and GSH level

Table 3 shows that injection of DIC led to a noticeable reduction $(P<0.05)$ in hepatic CAT and SOD activities in DIC-only treated group relative to the control animals. A considerable elevation $(P<0.05)$ in hepatic SOD and CAT activities was observed after treatment with silymarin in

Table 1. Effects of silymarin on serum ALT, AST, ALP and total bilirubin in the experimental groups

\begin{tabular}{|c|c|c|c|c|c|}
\hline Parameters & Group 1 & Group 2 & Group 3 & Group 4 & Group 5 \\
\hline ALT (U/L) & $26.13 \pm 5.73$ & $81.02 \pm 7.95^{\mathrm{a}}$ & $25.32 \pm 6.12^{b}$ & $38.09 \pm 4.53^{\mathrm{abc}}$ & $28.26 \pm 3.06^{\text {bd }}$ \\
\hline AST (U/L) & $50.66 \pm 2.28$ & $110.4 \pm 10.42^{\mathrm{a}}$ & $49.35 \pm 3.12^{b}$ & $62.12 \pm 3.62^{\mathrm{abc}}$ & $52.76 \pm 2.85^{\mathrm{bd}}$ \\
\hline $\operatorname{ALP}(U / L)$ & $139.4 \pm 4.75$ & $428.1 \pm 7.25^{\mathrm{a}}$ & $140.2 \pm 4.38^{b}$ & $252.32 \pm 5.85^{\mathrm{abc}}$ & $146.21 \pm 5.3^{\text {bd }}$ \\
\hline Total bilirubin (mg/dL) & $0.85 \pm 0.02$ & $2.4 \pm 0.05^{a}$ & $0.83 \pm 0.03^{b}$ & $1.02 \pm 0.04^{\mathrm{abc}}$ & $0.87 \pm .03^{\mathrm{bd}}$ \\
\hline
\end{tabular}

Data are expressed as mean \pm SEM $(n=8)$ and analyzed by one-way ANOVA followed by Tukey post hoc test. Group 1: control animals; Group 2: DIC-only treated animals; Group3: silymarin-only treated animals ( $200 \mathrm{mg} / \mathrm{kg}$ ); Groups 4 and 5: the animals were treated by DIC plus silymarin at doses of 100 $\mathrm{mg} / \mathrm{kg}$ and $200 \mathrm{mg} / \mathrm{kg}$, respectively. ${ }^{\mathrm{a}} P<0.05$ versus control animals (group 1 ), ${ }^{\mathrm{b}} P<0.05$ versus DIC-only treated animals (group 2 ), ${ }^{\mathrm{c}} P<0.05$ versus silymarin-only treated animals (group 3), ${ }^{\mathrm{d}} P<0.05$ versus animals treated by DIC plus silymarin at dose of $100 \mathrm{mg} / \mathrm{kg}$ (group 4 ). 
Ramezannezhad et al

Table 2. Effects of silymarin on FRAP, Nitrite content and MDA levels in the experimental groups

\begin{tabular}{|c|c|c|c|c|c|}
\hline Parameters & Group 1 & Group 2 & Group 3 & Group 4 & Group 5 \\
\hline Serum FRAP $(\mu \mathrm{M})$ & $526.27 \pm 31.22$ & $374.26 \pm 27.41^{a}$ & $618.67 \pm 50.21^{\mathrm{ab}}$ & $498 \pm 37.64^{b c}$ & $612.25 \pm 48.66^{\mathrm{abd}}$ \\
\hline Nitrite content ( $\mu \mathrm{M} / \mathrm{mg}$ tissue) & $5.63 \pm 0.21$ & $13.32 \pm 0.89^{a}$ & $5.51 \pm 0.32^{b}$ & $7.48 \pm 0.38^{\mathrm{abc}}$ & $5.56 \pm 0.28^{b d}$ \\
\hline Serum MDA (nmol/L) & $8.43 \pm 2.52$ & $19.68 \pm 3.18^{\mathrm{a}}$ & $7.96 \pm 2.39^{b}$ & $13.65 \pm 2.15^{\mathrm{abc}}$ & $8.17 \pm 1.87^{\mathrm{bd}}$ \\
\hline Liver MDA (nmol/mg protein) & $1.91 \pm 0.71$ & $5.51 \pm 1.15^{\mathrm{a}}$ & $1.80 \pm 0.67^{b}$ & $3.56 \pm 0.76^{\mathrm{abc}}$ & $1.87 \pm 0.58^{\mathrm{bd}}$ \\
\hline
\end{tabular}

FRAP (ferric reducing/antioxidant power), MDA (malondialdehyde).

Data are expressed as mean \pm SEM $(n=8)$ and analyzed by one-way ANOVA followed by Tukey post hoc test. Group 1: control animals; Group 2: DIC-only treated animals; Group3: silymarin-only treated animals ( $200 \mathrm{mg} / \mathrm{kg})$; Groups 4 and 5: the animals were treated by DIC plus silymarin at doses of 100 $\mathrm{mg} / \mathrm{kg}$ and $200 \mathrm{mg} / \mathrm{kg}$, respectively. ${ }^{a} P<0.05$ versus control animals (group 1 ), ${ }^{\mathrm{b}} P<0.05$ versus DIC-only treated animals (group 2 ), ${ }^{\mathrm{c}} P<0.05$ versus silymarin-only treated animals (group 3), ${ }^{\mathrm{d}} P<0.05$ versus animals treated by DIC plus silymarin at dose of $100 \mathrm{mg} / \mathrm{kg}$ (group 4 ).

Table 3. Effects of silymarin on CAT activity, SOD activity, GPx activity and GSH level in the experimental groups

\begin{tabular}{|c|c|c|c|c|c|}
\hline Parameters & Group 1 & Group 2 & Group 3 & Group 4 & Group 5 \\
\hline CAT (U/mg protein) & $165.32 \pm 14.32$ & $55.27 \pm 6.12^{\mathrm{a}}$ & $169.18 \pm 13.21^{\mathrm{b}}$ & $112.87 \pm 9.76^{\mathrm{abc}}$ & $167 \pm 15.13^{\text {bd }}$ \\
\hline SOD (U/mg protein) & $46.32 \pm 4.12$ & $27.61 \pm 2.89^{\mathrm{a}}$ & $48.96 \pm 5.11^{b}$ & $37.21 \pm 3.13^{\mathrm{abc}}$ & $47.43 \pm 3.98^{\mathrm{bd}}$ \\
\hline GPx (U/mg protein) & $26.34 \pm 0.89$ & $20.12 \pm 0.76^{\mathrm{a}}$ & $26.94 \pm 0.98^{b}$ & $23.12 \pm 0.61^{\mathrm{abc}}$ & $25.86 \pm 1.07^{\text {bd }}$ \\
\hline GSH ( $\mu \mathrm{mol} / \mathrm{g}$ tissue) & $12.89 \pm 0.11$ & $5.01 \pm 0.09^{a}$ & $13.11 \pm 0.19^{b}$ & $8.86 \pm 0.09^{a b c}$ & $13.02 \pm 0.17^{\mathrm{bd}}$ \\
\hline
\end{tabular}

CAT (catalase), SOD (superoxide dismutase), GPx (glutathione peroxidase), GSH (reduced form of glutathione). Data are expressed as mean \pm SEM ( $\mathrm{n}=8$ ) and analyzed by one-way ANOVA followed by Tukey post hoc test. Group 1: control animals; Group 2: DIC-only treated animals; Group3: silymarin-only treated animals ( $200 \mathrm{mg} / \mathrm{kg}$ ); Groups 4 and 5: the animals were treated by DIC plus silymarin at doses of $100 \mathrm{mg} / \mathrm{kg}$ and $200 \mathrm{mg} / \mathrm{kg}$, respectively. ${ }^{\text {a }} P<$ 0.05 versus control animals (group 1 ), ${ }^{b} P<0.05$ versus DIC-only treated animals (Group 2 ), ${ }^{c} P<0.05$ versus silymarin-only treated animals (group 3), ${ }^{d} P<0.05$ versus animals treated by DIC plus silymarin at dose of $100 \mathrm{mg} / \mathrm{kg}$ (group 4).

animals exposed to DIC. Table 3 also shows a remarkable decrease $(P<0.05)$ in liver GPx activity in the DIC-only treated group compared to the control animals. However, administration of silymarin at doses of 100 and $200 \mathrm{mg} /$ $\mathrm{kg}$ remarkably elevated liver GPx activity in DIC exposed rats. Also injection of DIC in DIC-only treated group led to a noticeable reduction $(P<0.05)$ in liver $\mathrm{GSH}$ relative to the control group (Table 3). Nevertheless, treatment with silymarin at doses of 100 and $200 \mathrm{mg} / \mathrm{kg}$ let to remarkable elevation $(P<0.05)$ in liver GSH in rats exposed to DIC.

The effects of silymarin on serum and gene expression of TNF- $\alpha$

Figure 1 shows the effects of silymarin on level of serum TNF- $\alpha$ and TNF- $\alpha$ gene expression. DIC injection in DIC-

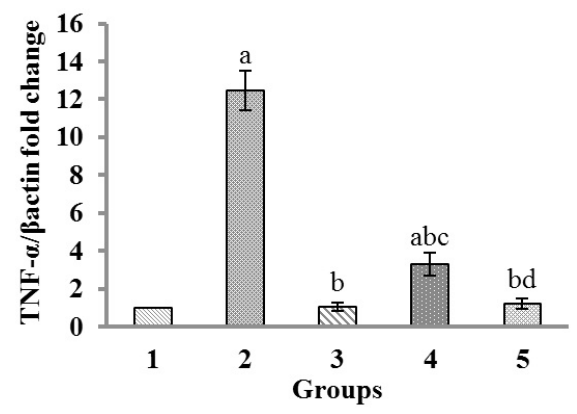

only treated group led to a remarkable increase $(P<0.05)$ in serum TNF- $\alpha$ level and TNF- $\alpha$ gene expression compared to the control group. Treatment with silymarin led to a noticeable reduction $(P<0.05)$ in level of serum TNF- $\alpha$ and TNF- $\alpha$ gene expression in DIC exposed animals. A remarkable change $(P<0.05)$ was seen in gene expression and serum level TNF- $\alpha$ in the group treated with silymarin at dose of $100 \mathrm{mg} / \mathrm{kg}$ in comparison with the group treated with silymarin at dose of $200 \mathrm{mg} / \mathrm{kg}$.

\section{Histopathological findings}

The histopathological results are demonstrated in Figure 2. The microscopic examination demonstrated normal structures of liver tissue from a control rat in the control group (Figure 2A). Injection of DIC in DIC-only treated

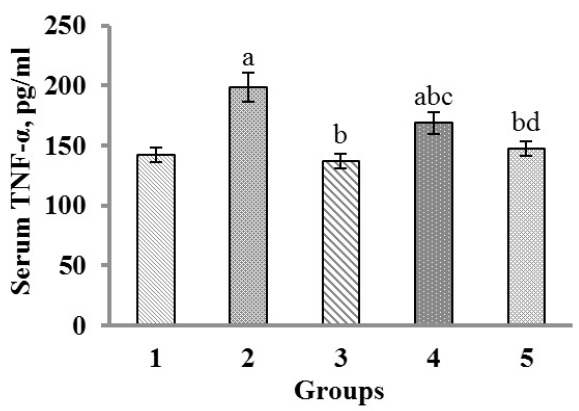

Figure 1. Effects of silymarin on serum tumor necrosis factor- $\alpha$ (TNF- $\alpha$ ) and expression of TNF- $\alpha$ in the experimental groups. Each value represents the mean \pm SEM of eight rats. Group 1: control animals; Group 2: DIC-only treated animals; Group3: silymarin-only treated animals (200 mg/kg); Groups 4 and 5: the animals were treated by DIC plus silymarin at doses of $100 \mathrm{mg} / \mathrm{kg}$ and $200 \mathrm{mg} / \mathrm{kg}$, respectively. ${ }^{\mathrm{a}} p<0.05$ versus control animals (group 1 ), ${ }^{b} p<0.05$ versus DIC-only treated animals (group 2), ${ }^{c} p<0.05$ versus silymarin-only treated animals (group 3 ), ${ }^{d} p<0.05$ versus animals treated by DIC plus silymarin at dose of $100 \mathrm{mg} / \mathrm{kg}$ (group 4). 


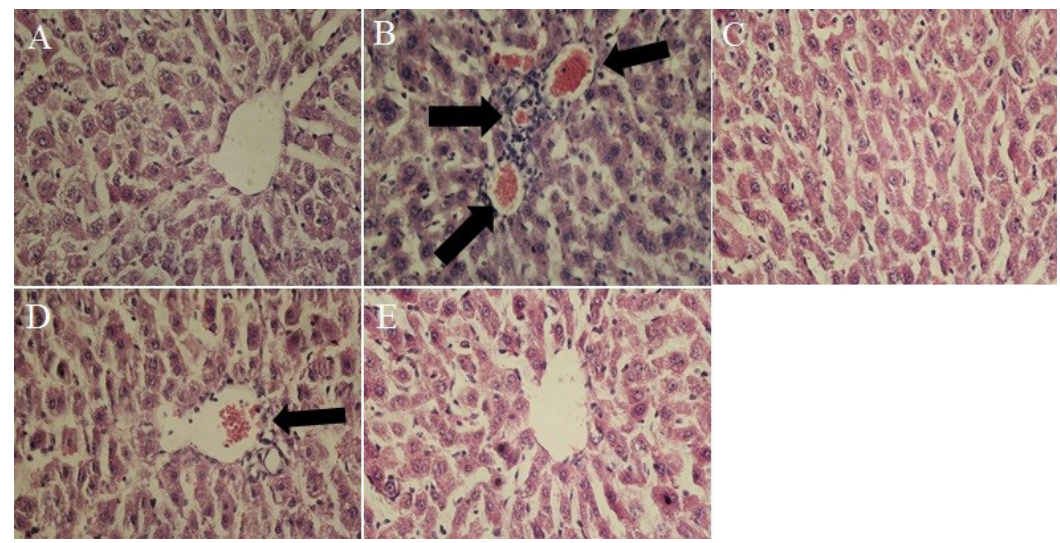

Figure 2. Effects of Silymarin on the liver histology of experimental groups. (A) Control animals with normal structure; (B) DIC-only treated animals show lymphocyte infiltration (the black arrows); (C) silymarin-only treated animals (200 mg/kg);(D) DIC-injected animals supplemented with silymarin (100 mg/kg); (D) DIC-injected animals supplemented with silymarin $(200 \mathrm{mg} / \mathrm{kg})$.

group demonstrated mononuclear cells infiltration and histological changes compared to the control group that reflected liver toxicity (Figure 2B). Treatment with silymarin led to a noticeable reduction in inflammatory cell infiltration in groups exposed to DIC (Figure 2D\&E). The decrease of inflammatory cells in treated group with silymarin at dose of $200 \mathrm{mg} / \mathrm{kg}$ was more than treated group with silymarin at dose of $100 \mathrm{mg} / \mathrm{kg}$.

\section{Discussion}

Our findings showed that DIC at $50 \mathrm{mg} / \mathrm{kg}$ induced liver toxicity in male rats and silymarin prevented its hepatotoxic effects. The release of specific enzymes such as AST, ALT, and ALP into circulatory system is one of the most sensitive signs of liver damage. In our study noticeable elevation was seen in the contents of total bilirubin, AST, ALT and ALT in DIC-only treated group (Table 1) compared to the control animals which approved the liver toxicity potential of DIC. These results are in agreement with prior reports $(5,14,27)$. In this study treatment with silymarin at doses of 100 and $200 \mathrm{mg} / \mathrm{kg}$ reversed changes induced by DIC in the contents of ALT and AST. This indicates that silymarin protected the structural integrity of liver cell membranes and eventually inhibited the leakage of these enzymes into circulatory system. The elevation in the contents of total bilirubin and ALP observed in the DIC-only treated animals is a marker of cholestasis in obstructive jaundice (28). Cysteinyl leukotrienes play an important role in inflammatory responses and the escalation of cholestasis in obstructive jaundice (28). In this research, reduction in levels of total bilirubin and ALP in silymarin treated groups may be linked with its anti-inflammatory and antioxidant properties. There seems to be difference in the effect of silymarin at doses of 100 and $200 \mathrm{mg} / \mathrm{kg}$ on these markers. Therefore, it can be said that the effect of silymarin on these biochemical markers is dose sensitive.

Histopathological studies of DIC-only treated group depicted increased lymphocyte infiltration and apoptotic changes, which show liver toxicity induced by DIC in rats according to prior investigations $(14,27)$. Remarkable recovery towards normal liver histopathology in silymarin administrated groups further supported the protective effect of silymarin on DIC-induced hepatotoxicity.

MDA is a reliable marker for lipid peroxidation (LPO). Increased LPO by DIC as one of the signs for oxidative stress published previously by various studies $(14,27$, 29). In this research, DIC-induced liver toxicity led to a noticeable elevation in the content of MDA in serum and hepatic tissue relative to the control animals that is in line with the prior published investigations $(5,30,31)$. On the other hand, administration of silymarin not only increased the FRAP content in plasma but also decreased the MDA level in the serum and hepatic tissue in rats exposed to DIC. The elevated FRAP content and decreased LPO level in silymarin treated groups might be due to direct increase in GSH content or due to its free radical scavenging property.

Increase in level of nitrite in DIC-only treated rats indicated the effect of NO in liver toxicity induced by DIC. Our results are in line with the prior studies that have shown NO creates important role in chemical toxicity (32, 33). Remarkable reduction of nitrite content in silymarin treated groups suggested that this antioxidant offered liver protection in DIC exposed rats by reduce the NO content and nitrosative stress.

Intracellular glutathione (GSH), the principal endogenous antioxidant, creates a critical role in defense of cell on damage induced by oxidative stress. Both in vivo and in vitro studies have shown the effect of GSH depletion in oxidative stress induced by DIC in various model systems $(27,30,34)$. In our research, DIC-induced liver toxicity led to a noticeable reduction in the content of GSH in liver tissues relative to the control animals. On the other hand, a noticeable recovery of GSH level was observed in silymarin administrated groups. GSH recovery may be due to the ability of silymarin to reduce oxidative stress or to increase the GSH content directly. In order to survey the role of silymarin on metabolism of 
GSH, ourstudyassessed its roleon GPxas GSH metabolizing enzyme. GPx simplifies peroxides neutralization via react with GSH and leading to increased contents of GSSG (oxidized glutathione), that is then reduced by glutathione reductase return to the GSH thereby maintaining the antioxidant content. DIC-induced changes in activity of GPx have been indicated previously $(14,30)$. In our study, DIC-induced increase in GPx activity (Table 3) may be due to the defense mechanism against elevated LPO and noticeable reduction in GPx activity in the treated groups with silymarin can be due to the decrease levels of LPO or oxidative stress.

Previous investigations have indicated that injection of DIC causes a remarkable reduction in CAT and SOD in animals $(5,14,30)$. In our investigation, injection of DIC caused the reduction in activities of CAT and SOD. On the other hand, treatment with silymarin remarkably restored these alterations of enzymatic activities in animals. The decrease in SOD and CAT activities in silymarin treated rats could be due to antioxidant properties of silymarin.

TNF- $\alpha$ is a cytokine which releases in the inflammatory conditions and migration of macrophages. TNF- $\alpha$ leads to oxidative stress which in turn increases the liver cells damage (35). Previous researches have shown that injection of DIC led to remarkable elevate in serum level of TNF- $\alpha$ and its gene expression in hepatic tissue $(5,14,30)$. The result of our study showed that liver TNF- $\alpha$ gene expression and serum TNF- $\alpha$ content elevated remarkably in the DIC-only treated group relative to the control animals. In our investigation, liver TNF- $\alpha$ gene expression and serum TNF- $\alpha$ level significantly decreased in the silymarin-treated rats. Thus, the decrease in TNF- $\alpha$ serum content and expression of TNF- $\alpha$ is another obvious, at least partly, which confirms the liver protective role of silymarin due to its antioxidant properties.

\section{Conclusion}

Our study indicates that silymarin has protective effect against DIC-induced liver toxicity in rats. Also, silymarin as a natural component due to its anti-inflammatory and antioxidant properties may lead to improvement in complications of DIC consumption such as liver toxicity.

\section{Acknowledgments}

We would like to express our gratitude to those who have helped us in Clinical Biochemistry Research Center of Shahrekord University of Medical Sciences.

\section{Authors' contributions}

Designing the study, data analysis and preparation of the manuscript was done by AN and PR. Authors read and approved the final manuscript.

\section{Conflict of interests}

The authors declared no competing interests.

\section{Ethical considerations}

The study was approved by the Ethical Committee of Shahrekord University of Medical Sciences, Shahrekord, Iran (Ethic number: IR. SKUMS. REC. 94. 146). Ethical issues (including plagiarism, data fabrication, double publication) have been completely observed by the authors.

\section{Funding/Support}

This research was financially supported by Shahrekord University of Medical Sciences, Shahrekord, Iran (grant no. 2640).

\section{References}

1. Labbe G, Pessayre D, Fromenty B. Drug-induced liver injury through mitochondrial dysfunction: mechanisms and detection during preclinical safety studies. Fundam Clin Pharmacol. 2008;22(4):335-53. doi: 10.1111/j.14728206.2008.00608.x.

2. Boelsterli UA. Mechanisms underlying the hepatotoxicity of nonsteroidal antiinflammatory drugs. In: Kaplowitz N, DeLeve LD, eds. Drug-Induced Liver Disease. 3rd ed. Elsevier; 2013:343-67.

3. Masubuchi Y, Saito H, Horie T. Structural requirements for the hepatotoxicity of nonsteroidal anti-inflammatory drugs in isolated rat hepatocytes. J Pharmacol Exp Ther. 1998;287(1):208-13.

4. Todd PA, Sorkin EM. Diclofenac sodium. A reappraisal of its pharmacodynamic and pharmacokinetic properties, and therapeutic efficacy. Drugs. 1988;35(3):244-85. doi: 10.2165/00003495-198835030-00004.

5. Adeyemi WJ, Olayaki LA. Diclofenac - induced hepatotoxicity: Low dose of omega-3 fatty acids have more protective effects. Toxicol Rep. 2018;5:90-5. doi: 10.1016/j. toxrep.2017.12.002.

6. Siu WP, Pun PB, Latchoumycandane C, Boelsterli UA. Baxmediated mitochondrial outer membrane permeabilization (MOMP), distinct from the mitochondrial permeability transition, is a key mechanism in diclofenac-induced hepatocyte injury: Multiple protective roles of cyclosporin A. Toxicol Appl Pharmacol. 2008;227(3):451-61. doi: 10.1016/j.taap.2007.11.030.

7. Galati G, Tafazoli S, Sabzevari O, Chan TS, O’Brien PJ. Idiosyncratic NSAID drug induced oxidative stress. Chem Biol Interact. 2002;142(1-2):25-41.

8. Gil ML, Ramirez MC, Terencio MC, Castell JV. Immunochemical detection of protein adducts in cultured human hepatocytes exposed to diclofenac. Biochim Biophys Acta. 1995;1272(3):140-6.

9. Lim MS, Lim PL, Gupta R, Boelsterli UA. Critical role of free cytosolic calcium, but not uncoupling, in mitochondrial permeability transition and cell death induced by diclofenac oxidative metabolites in immortalized human hepatocytes. Toxicol Appl Pharmacol. 2006;217(3):322-31. doi: $10.1016 /$ j.taap.2006.09.012.

10. Dykens JA, Will Y. The significance of mitochondrial toxicity testing in drug development. Drug Discov Today. 2007;12(17-18):777-85. doi: 10.1016/j.drudis.2007.07.013.

11. Wellington K, Jarvis B. Silymarin: a review of its clinical 
properties in the management of hepatic disorders. BioDrugs. 2001;15(7):465-89. doi: 10.2165/00063030200115070-00005.

12. Taleb A, Ahmad KA, Ihsan AU, Qu J, Lin N, Hezam K, et al. Antioxidant effects and mechanism of silymarin in oxidative stress induced cardiovascular diseases. Biomed Pharmacother. 2018;102:689-98. doi: 10.1016/j. biopha.2018.03.140.

13. Borsari M, Gabbi C, Ghelfi F, Grandi R, Saladini M, Severi $\mathrm{S}$, et al. Silybin, a new iron-chelating agent. J Inorg Biochem. 2001;85(2-3):123-9.

14. Peter SJ, Basha SK, Giridharan R, Lavinya BU, Sabina EP. Suppressive effect of Spirulina fusiformis on diclofenacinduced hepato-renal injury and gastrointestinal ulcer in Wistar albino rats: A biochemical and histological approach. Biomed Pharmacother. 2017;88:11-8. doi: 10.1016/j.biopha.2017.01.032.

15. Kropacova K, Misurova E, Hakova H. Protective and therapeutic effect of silymarin on the development of latent liver damage. Radiats Biol Radioecol. 1998;38(3):411-5.

16. Impellizzeri D, Bruschetta G, Ahmad A, Crupi R, Siracusa R, Di Paola R, et al. Effects of palmitoylethanolamide and silymarin combination treatment in an animal model of kidney ischemia and reperfusion. Eur J Pharmacol. 2015;762:136-49. doi: 10.1016/j.ejphar.2015.05.010.

17. Zaidi SNF, Mahboob T. Prevention of liver cirrhosis by Silymarin. Pak J Pharm Sci. 2017;30(4):1203-11.

18. Heidarian E, Soofiniya Y. Hypolipidemic and hypoglycemic effects of aerial part of Cynara scolymus in streptozotocininduced diabetic rats. J Med Plant Res. 2011;5(13):2717-23.

19. Ahmad I, Kumar A, Shukla S, Prasad Pandey H, Singh C. The involvement of nitric oxide in maneb- and paraquatinduced oxidative stress in rat polymorphonuclear leukocytes. Free Radic Res. 2008;42(10):849-62. doi: $10.1080 / 10715760802513733$.

20. Ellman GL. Tissue sulfhydryl groups. Arch Biochem Biophys. 1959;82(1):70-7.

21. Hafeman DG, Sunde RA, Hoekstra WG. Effect of dietary selenium on erythrocyte and liver glutathione peroxidase in the rat. J Nutr. 1974;104(5):580-7. doi: 10.1093/ jn/104.5.580.

22. Heidarian E, Saffari J, Jafari-Dehkordi E. Hepatoprotective action of Echinophora platyloba DC leaves against acute toxicity of acetaminophen in rats. J Diet Suppl. 2014;11(1):53-63. doi: 10.3109/19390211.2013.859217.

23. Flohe L, Otting F. Methods in enzymology. Oxygen radicals in biological systems. New York: Academic Press; 1984:93104.

24. Bradford MM. A rapid and sensitive method for the quantitation of microgram quantities of protein utilizing the principle of protein-dye binding. Anal Biochem. 1976;72:248-54.

25. Hosseinzadeh M, Omidifar N, Dehghanian AR, Kumar PV, Meshkibaf MH. Histopathological changes in rabbit gastric mucosa after chronic exposure to pickled vegetables: an experimental study. Nutr Cancer. 2013;65(7):1042-4. doi: 10.1080/01635581.2013.810293.

26. Nili-Ahmadabadi A, Tavakoli F, Hasanzadeh G, Rahimi $\mathrm{H}$, Sabzevari O. Protective effect of pretreatment with thymoquinone against Aflatoxin $\mathrm{B}(1)$ induced liver toxicity in mice. Daru. 2011;19(4):282-7.

27. Alabi QK, Akomolafe RO, Olukiran OS, Adeyemi WJ, Nafiu AO, Adefisayo MA, et al. The Garcinia kola biflavonoid kolaviron attenuates experimental hepatotoxicity induced by diclofenac. Pathophysiology. 2017;24(4):281-90. doi: 10.1016/j.pathophys.2017.07.003.

28. Uemura M, Kojima H, Buchholz U, Kikuchi E, Matsumoto M, Kikukawa M, et al. Cysteinyl leukotrienes in the bile of patients with obstructive jaundice. J Gastroenterol. 2002;37(10):821-30. doi: 10.1007/s005350200136.

29. Nouri A, Heidarian E. Nephroprotective effect of silymarin against diclofenacinduced renal damage and oxidative stress in male rats. J Herbmed Pharmacol. 2019;8(2):14652. doi: 10.15171/jhp.2019.23.

30. Ahmad I, Shukla S, Kumar A, Singh BK, Kumar V, Chauhan $\mathrm{AK}$, et al. Biochemical and molecular mechanisms of $\mathrm{N}$-acetyl cysteine and silymarin-mediated protection against maneb- and paraquat-induced hepatotoxicity in rats. Chem Biol Interact. 2013;201(1-3):9-18. doi: 10.1016/j. cbi.2012.10.027.

31. Nouri A, Heidarian E, Nikoukar M. Effects of N-acetyl cysteine on oxidative stress and TNF-alpha gene expression in diclofenac-induced hepatotoxicity in rats. Toxicol Mech Methods. 2017;27(8):561-7. doi: $10.1080 / 15376516.2017 .1334732$.

32. Safari T, Miri S, Kourkinejad Gharaei F, Nazri Panjaki A, Saeidienik F, Bagheri H, et al. Nitric oxide metabolite changes in gentamicin-induced nephrotoxicity; the effects of antioxidant vitamins. J Renal Inj Prev. 2018;7(3):201-5. doi: 10.15171/jrip.2018.47.

33. Guan LY, Fu PY, Li PD, Li ZN, Liu HY, Xin MG, et al. Mechanisms of hepatic ischemia-reperfusion injury and protective effects of nitric oxide. World J Gastrointest Surg. 2014;6(7):122-8. doi: 10.4240/wjgs.v6.i7.122.

34. Niu X, de Graaf IA, van de Vegte D, Langelaar-Makkinje M, Sekine S, Groothuis GM. Consequences of Mrp2 deficiency for diclofenac toxicity in the rat intestine ex vivo. Toxicol In Vitro. 2015;29(1):168-75. doi: 10.1016/j.tiv.2014.10.004.

35. Tracey KJ. The inflammatory reflex. Nature. $2002 ; 420(6917): 853-9$. 